\title{
An illocutionary account of reportative evidentials in imperatives*
}

\author{
Scott AnderBois \\ Brown University
}

\begin{abstract}
This paper provides a detailed analysis of reportative evidentials in imperative sentences, drawing on original fieldwork in Tagalog and Yucatec Maya. Previous literature presents two distinct views of such sentences, which we dub 'imperative-by-proxy' and 'neutral report' views. Based on a range of data across different sorts of imperatives uses in different sorts of contexts, we argue for a version of the 'imperative-by-proxy' theory and proposal a formal analysis with theory of illocutionary updates.
\end{abstract}

Keywords: illocutionary mood, imperatives, reportatives, Tagalog, Yucatec Maya

\section{Introduction}

Evidentials are often described as functional morphemes that encode the speaker's information source for the claim they are making. While this description is roughly appropriate for evidentials in declarative sentences, evidentials also occur in other sentence types in some, but not all, languages. Where possible, it is often the case that only a proper subset of evidentials is possible, as Aikhenvald (2004: pp. 242-9) describes in some length for interrogative sentences. Despite their more restricted use compared to declaratives, the meaning/use of evidentials in interrogatives has been quite informative about the nature of evidentials and the structure of illocutionary updates more generally (e.g. Murray (2010, 2011, 2014), Lim (2010)).

Beyond interrogatives, however, interactions between non-declarative sentences and evidentials remain largely unexplored. In particular, imperatives in a number of unrelated languages allow for reportative evidentials, as in (1) from Tagalog. ${ }^{1}$

* Thanks to Rosa Isela Canche Cen, Miguel Oscar Chan Dzul, Margarita Hau Hau, Norma Patricia Kuyoc Kuyoc, Irma Yolanda Pomol Cahum, and Luis Petul for Yucatec Maya judgments and feedback! Thanks to Henrison Hsieh, Jenny Tan, and Amber Teng for their Tagalog judgments and feedback. Thanks also to Polly Jacobson, Sarah Murray, Kyle Rawlins, Vesela Simeonova, 6 anonymous SALT 27 reviewers, and audiences at SAIL 2017, SALT 2017, and Brown's LingLangLunch for helpful comments.

1 The following abbreviations are used for glosses: DEF: definite article, DIR: direct case, IMP: imper-

C2017 AnderBois 
AnderBois
(1)
Kumuha ka daw ng tinapay.
take.AGT.TRIG you.DIR REP INDIR bread
'Take some bread (she says/they say)!'

Tagalog

Previous literature has noted that such sentences are possible in several languages and made some informal claims about the interpretation of imperative sentences with reportative evidentials (henceforth, $\mathrm{IMP}_{\mathrm{REP}}$ ). Even at this relatively informal level, however, two clearly distinct views exist about the meaning of such sentences. On the one hand, Aikhenvald (2010: p. 138) describes IMPREP thusly: 'not just 'hearsay' — it implies a command to do something on someone else's order', what I will call IMPERATIVE B Y PROXY. On the other hand, Schwager (2010: p. 8) describes IMP $_{\text {REP }}$ as 'not an imperative on behalf of a third party, but rather an entirely neutral report of an imperative' (see Thomas (2014), Korotkova (2015), Korotkova (2016) for related views), what I will call a NEUTRAL REPORT view. Fleshing these two views, then, we can think of the IMPERATIVE BY PROXY view as holding that IMP $_{\text {REP }}$ contribute the same primary meanings/updates as other imperatives, whereas the NeUtRAL REPORT holds that they contribute informational updates whose content is a report or quote whose contents are imperative-like.

Beyond the general sparsity of data on $\mathrm{IMP}_{\mathrm{REP}}$, two particular aspects of previous literature make it hard to adjudicate between these two views. First, as is plain from Aikhenvald (2010)'s quote above, the literature on IMP REP $_{\text {typically focuses }}$ exclusively on command-like uses, ignoring the wide range of other functions served by imperative sentences generally (e.g. wishes, advice, requests). Second, previous literature typically provides example sentences in isolation, without the surrounding discourse contexts in which they may occur.

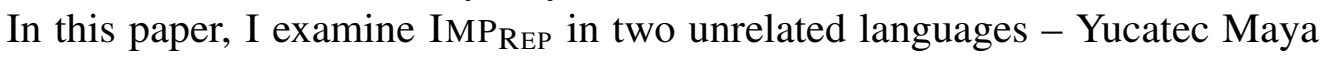
and Tagalog - and argue for a version of the IMPERATIVE B Y PROXY view based on data from context-relative felicity judgments. As has been argued for certain readings of interrogatives with reportatives, I argue that an illocutionary account of IMPREP is needed. Specifically, I develop an account within a Farkas \& Bruce (2010)-style scoreboard semantics, building on AnderBois (2014)'s account of reportatives in declarative sentences. The rest of the paper is structured as follows. $\$ 2$ reviews properties of evidentials with an eye towards distinguishing them from related constructions (e.g. quotatives), some of which interact differently with

fective aspect, IMPER: imperative, INDIR: indirect case, MIR: mirative, NEG: negation, NEG.CL: negative/extrafocal clitic, OBL: oblique case, PFV: perfective aspect, PL: plural, PREP: preposition, PRES: presentative, PROG: progressive aspect, REL: relational noun suffix, SUBJ: subjunctive mood, TOP: topic marker, For agreement morphology in YM, I follow the terminological tradition among Mayanists, referring to Set $\mathrm{A}(\approx$ Ergative/Nominative) and Set B $(\approx$ Absolutive/Accusative $)$ markers, e.g. A3 $=3$ rd person Ergative/Nominative. B3 is phonologically null and therefore left unglossed. All examples are elicited unless otherwise noted. 
An illocutionary account of reportative evidentials in imperatives

imperatives; $\S 3$ examines the illocutionary effects of IMP REP $_{\text {in discourse including }}$ the range of responses they elicit; $\$ 4$ looks at two different types of 'softening' claimed to happen in $\mathrm{IMP}_{\mathrm{REP}} ; \S 5$ develops an illocutionary analysis of $\mathrm{IMP}_{\mathrm{REP}}$ in a scoreboard semantics; $\$ 6$ concludes including discussing implications for the typology of evidentials.

\title{
2 Reportatives defined
}

Before proceeding, I first provide brief background on the two languages examined here, including the properties of the clitic particle categories to which the reportative markers in the two languages belong. Yucatec Maya (YM) is one of 30 languages in the Mayan family, spoken by $\approx 759,000$ people (2005 census) across the Mexican states of Campeche, Quintana Roo, and Yucatán (INEGI (2009)). Tagalog is an Austronesian language of the Phillippines spoken as the first language of an estimated 28 million speakers. Both languages have verb-initial basic word order with surface word order driven largely by discourse-related factors including preverbal topic and focus constructions.

Unlike many of the languages where evidentials have been investigated in the most detail, neither YM nor Tagalog are languages with inflectional paradigms of evidentials. Rather, the Tagalog reportative daw (or its variant raw) is a member of a set of 18 second-position clitics conveying a variety of different modal, information, structural, and other 'discourse-related' meanings (see Schachter \& Otanes (1972: pp. 411-435) for comprehensive description). YM similarly lacks a paradigm of evidentials, but its reportative, bin, is a member of a small set of clitics whose linear position is preferentially second position, but quite flexible. Other members of this class, whose formal properties are described in a bit more detail by AnderBois (ms) include mirative bakáan, polar question wáa(j), frustrative lo'obal, and túun 'then'.

Despite the clear difference in the languages' evidential systems more generally, YM bin and Tagalog daw nonetheless share several core properties in their use in declarative sentences that we take to distinguish them from other secondhand/quotational constructions across languages (i.e. from things other than reportative evidentials). First, bin or daw in simple declaratives indicates the information source the speaker has for their claim. In contrast, a morpheme like Kallaalisuut $=$ guuq not only has such uses but also has directive uses even in declarative sentences as in (2) from Bittner (2014: p. 144).

$$
\begin{aligned}
& \text { Su-si-nngit-la-nga=guuq } \\
& \text { what-get-not-DECL-1sg=REP }
\end{aligned}
$$

'Tell [her], I didn't buy anything.'

\author{
Kalaallisut
}


Second, although the identity of the reporter may be clear in context, as in (3a), reportatives like daw and bin do not allow for the reporter to be overtly expressed in any way. For example, attempts to make this apparently anaphoric link explicit as a pronoun or proper name, (3b), or via agreement, (3c) are ungrammatical. Finally, in (3d), we see for YM that the desire to make explicit the reporter's identity does not license a clausal topic, even though nothing rules out the reporter being coreferential with an independently licensed clausal topic.

(3) Scenario: I was talking to my friend Luis earlier about the Xtáabay (a mythical woman who seduces and attacks drunk men in the jungle) and now tell you:

a. Chowak bin u tso'ots-el u pool le ixtáabay=o'. long REP A3 hair-REL A3 head DEF Xtáabay=DistAL 'I was told (by Luis) that the Xtáabay's hair is long.' Yucatec Maya

b. * Chowak bin \{leti'/Luis $\}$ u tso'ots-el u pool le ixtáabay=o'. long REPhim/Luis A3 hair-REL A3 head DEF Xtáabay=DistAL Intended *'I was told by $\{$ him/Luis $\}$ that the Xtáabay's hair is long.'

c. * Chowak u bin u tso'ots-el u pool le ixtáabay=o'. long A3 REP A3 hair-REL A3 head DEF Xtáabay=DistAL Intended *'I was told by him/her that the Xtáabay's hair is long.'

d. * Luis=e' chowak bin u tso'ots-el u pool le ixtáabay=o'. Luis=Top long REP A3 hair-REL A3 head DEF Xtáabay=DISTAL Intended *'As for Luis, I was told by him that the Xtáabay's hair is long.'

This contrasts, for example, with another construction in YM, what Lucy (1993) calls the QUOTATIVE, which inflects with absolutive agreement for the original source (e.g. $k(i j)$ 'he says/said', keen 'I say/said') and optionally for the recipient of the original quote. ${ }^{2}$

$$
\begin{aligned}
& \text { Xeen - kij (tech). } \\
& \text { go.IMPER QUOT.3SG DAT.2SG } \\
& \text { "Go", he said/says (to you)' }
\end{aligned}
$$

In addition to the use with an apparently anaphoric reporter in (3a), reportatives can also be used in cases with indefinite-like (or perhaps generic-like) reporters, as in (5). While some accounts regard the reporter as an implicit argument, note that this

2 Ceong (2016) similarly claims that the Korean 'reportative' $-y$ /-tay inflect for person and therefore would not be considered within the scope of the present inquiry. Ceong (2016) briefly discussed imperatives with this marker, but beyond establishing their grammaticallity, more work is needed to understand how they are interpreted. 
An illocutionary account of reportative evidentials in imperatives

argument does not fit cleanly within the traditional indefinite/definite divisions such as Fillmore (1969) (though see AnderBois (2012) for a class of 'flexible' implicit arguments in English which come much closer).

(5) Scenario: We are discussing our opinions about a local politician.

Matapat daw siya. honest REP DIR.3SG

'He's honest, I heard.' (alt. 'He's honest, they say.') Tagalog

Finally, while reportatives may convey reduced speaker commitment, they are typically used in 'veridical' ways as claimed by Faller (2007)) for Cuzco Quechua $=s i$, i.e. as though the speaker believes the scope proposition is at least possibly true. Despite this general tendency, as described in detail across languages by AnderBois (2014), the scope proposition of REP can - given a perspectivally rich context - be explicitly denied by the same speaker, as in (6) and (27).

(6) Scenario: We are discussing our opinions about a local politician.

Matapat daw siya, pero hindi naman iyon totoo.

honest REP DIR.3Sg but NEg CONTR that true

'He's honest, they say, but it's not really true.'

Tagalog

Having shown that the use of Tagalog daw and YM bin in declaratives shares many core properties with reportatives in other languages, we return now to our main topic: reportatives in imperative sentences.

\section{IMP $_{\text {REP }}$ in discourse}

Imperatives are a major syntactic sentence type across languages. Although imperatives are often associated with directive speech acts like commands, they also have a range of non-directive functions they readily serve cross-linguistically (see Aikhenvald (2010), Condoravdi \& Lauer (2012) for recent overviews). That is to say, they are polyfunctional, being usable to perform a wide range of (direct) speech act functions compared with, say, declarative sentences.

(7) Imperative speech acts:
a. Stand at attention! $\rightsquigarrow$ COMMAND
b. Please, don't be rain! $\rightsquigarrow$ WISH
c. Have a cookie. $\rightsquigarrow$ OFFER
d. Take the train that leaves in 10 minutes. $\rightsquigarrow$ ADVICE 
As noted above, one of the limitations of previous discussion on IMPREP is that it

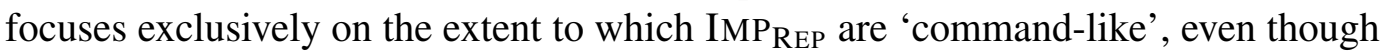
imperative sentences in the first place need not be very command-like. One of our goals here, then, is to consider IMP $\mathrm{REP}_{\mathrm{P}}$ across a variety of different possible functions of sort surveyed in (7).

\subsection{Illocutionary force of IMP REP $_{\text {in discourse }}$}

The ImPerative by PROXY and Neutral Report views present contrasting characterizations of the type of update encoded by IMPREP. The most direct way to distinguish between these theories empirically, then, is by seeing what kinds of

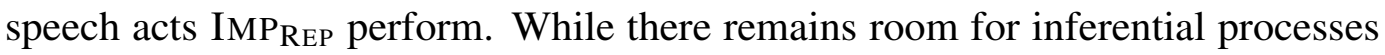
that affect the speech act such sentence can be used to perform (e.g. as seen in imperative polyfunctionality), the two theories nonetheless make clearly distinct predictions. The IMPERATIVE BY PROXY view, as the name suggests, predicts that

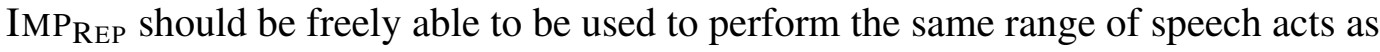
other imperatives. The NEUTRAL REPORT view, on the other hand, predicts that IMP $_{\text {REP }}$ should be freely able to be used to perform the same range of speech acts as declaratives, with any imperative-like uses being instances of indirect speech acts (or perhaps perlocutionary effects of declarative-like speech acts).

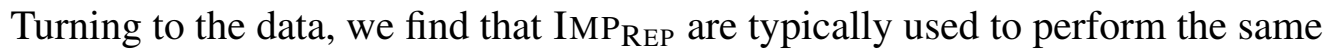
range of speech acts as imperatives (illustrated here with examples from YM). This includes command uses as in (8a), but also other uses typically associated with imperatives, $(8 \mathrm{~b}-8 \mathrm{~d})$.

(8) a. Order Scenario: Our mother has told me to make sure that my younger sibling eats their dinner. After talking to her, I tell my sibling:

Uk' bin a wo'och k'eyem=o'

drink.IMPER REP your meal pozole-DISTAL

'Drink your pozole (she orders)!'

Yucatec Maya

b. Advice Scenario: Your stomach hurts and I am on the phone with our Mom asking for advice. I tell you:

Uk' bin a wo'och k'eyem=o'

drink.IMPER REP your meal pozole-DISTAL

'Drink your pozole (she says)!'

Yucatec Maya

c. Offer Scenario: A child's mother has told them they should offer cake to guests. The child says to a guest:

Jaant bin le paastel=a'

eat.IMPER REP DEF cake=DISTAL

'Eat this cake (Mom told me to offer it)!

Yucatec Maya 
An illocutionary account of reportative evidentials in imperatives

d. Well-wish scenario: My friend wants me to tell you to take care. I say to you:

Kaláant a baj bin!

care.for.IMPER A2 REFL REP

'Take care (s/he says)!'

Yucatec Maya

Beyond positive imperative forms, other related forms similarly are possible and seemingly retain their characteristic effects as well:

(9) a. Optative: A friend told me to wish you well. I say:

Káa xi'ik bin tech uts

IRR go.SUBJ REP DAT.B2SG good

'May you be well (my friend wishes)!' Yucatec Maya

b. Exhortative: My friend told us Ko'ox janal! 'Let's eat!'. You didn't hear what was said and so I repeat for you:

Ko'ox bin janal.

come.HORT REP eat

'Let's eat (she says).'

Yucatec Maya

c. Negative imperative: Juan says he is going to kill one of his father's pigs. I am on the phone with Juan's dad and say:

Ma' bin a kíinsik (le k'éek'en=o')!

NEG REP A2 kill DEF pig=DistAL

'Don't kill the pig (he says)!'

Yucatec Maya

Conversely, IMP $P_{\text {ReP }}$ are infelicitous in information-seeking contexts such as ones in which the question under discussion concerns what the speaker heard or what the speaker wants. ${ }^{3}$

(10) Xeen bin a maan bu'ul go.IMP REP A2 buy.SUBJ bean

'Go buy beans (I heard).'

Yucatec Maya

a. \#Information-seeking scenario: You talked to Mom, what did you hear?

b. \#Descriptive bouletic modal scenario: You talked to Mom, what does Mom want?

3 Constructing these examples is a bit tricky since we need to make sure we have a context where the corresponding ordinary imperative is not felicitous. This means that certain other deontic modals are rule out since such imperatives are felicitous even without the reportative:

(i) a. What does my dad think I should do?

b. Go buy beans. 
c. $\checkmark$ Order scenario: My mother realized we were out of beans and told my younger brother to tell me, outside, to go buy some.

In sum, utterances of IMP $\mathrm{REP}_{\text {in }} \mathrm{YM}$ contribute the full range of speech acts possible with imperatives more generally, but are infelicitous in uses that are most associated with declaratives, such as making factual claims. This range of uses is expected under the IMPERATIVE BY PROXY but surprising under the NEUTRAL REPORT view. This is especially true of the infelicity of IMPREP in informationseeking contexts, as in (10), since these should be the most readily available uses under the NEUTRAL REPORT view.

\subsection{Responding to IMP $\mathrm{IMP}_{\mathrm{R}}$}

In addition to the range of possible speech acts in which IMP $_{\text {REP }}$ may be used, further support for the IMPERATIVE B Y PROXY theory comes from the range of possible responses to IMPREP in discourse. While declarative sentences do not oblige an overt response, a number of recent works have explored the range of possible responses to declaratives across languages (e.g. Gunlogson (2001), Farkas \& Bruce (2010), Farkas \& Roelofsen (2015)). While declaratives typically do not oblige any overt linguistic response, one specific conclusion of these works is that responses like 'yes' and 'no' associated with interrogatives are also possible with declaratives. In contrast, many of these same responses, such as English 'yes', are infelicitous as responses to imperatives.

Since declarative and imperative updates show different response patterns, we find again that the two characterizations of IMP $\mathrm{REP}_{\mathrm{P}}$ produce quite different predictions. If IMP REP contribute neutral reports, they ought to allow for the same pattern of responses as declaratives do generally. The IMPERATIVE BY PROXY view predicts that they should allow for the same range of responses as other imperatives, crucially disallowing responses such as 'Yes' and 'That's true.' that are typical for declaratives.

Turning to the data, IMP REP pattern with other imperatives, therefore supporting the IMPERATIVE BY PROXY view. For positive responses as in (11a), typical responses for declaratives such as jaaj 'true' and repeating the first prosodic word of the verb phrase are infelicitous. Conversely, felicitous responses to positive imperatives include simply performing the action in question or replying with ma'alob túun 'ok, then'. For negative responses, the simplest response for declaratives, $m a$ ' 'no' is felicitous, but interpreted as a denial that the speaker will perform the action rather than a denial that a third party issued an imperative. This is further confirmed by the asymmetry between responses in (11b) which specifically talk about truth and those which do not. 
An illocutionary account of reportative evidentials in imperatives

A: Uk' bin a wo'och k'eyem=o' drink.IMPER REP your meal pozole-DISTAL

'Drink your pozole (she orders)!'

\section{Yucatec Maya}
a. B: Ma’alob túun. // \#Jaaj // \#Uk'. okay then true drink.IMPER
'Okay then.' // \#‘True.' // \#'Yes.'

b. B: Ma', (min jantik). // Mix táan. // \#Ma' jaaj=i'.

No Neg.1SG eat Neg Prog NEG true=NeG.CL

'No, (I won't).' // 'I won't.' // \#'It's not true.'

For YM, IMPREP pattern with other imperatives, as expected under the IMPERATIVE BY PROXY view. For Tagalog, however, Schwager (2010) claims that IMPREP are neutral reports and offers the following as support:

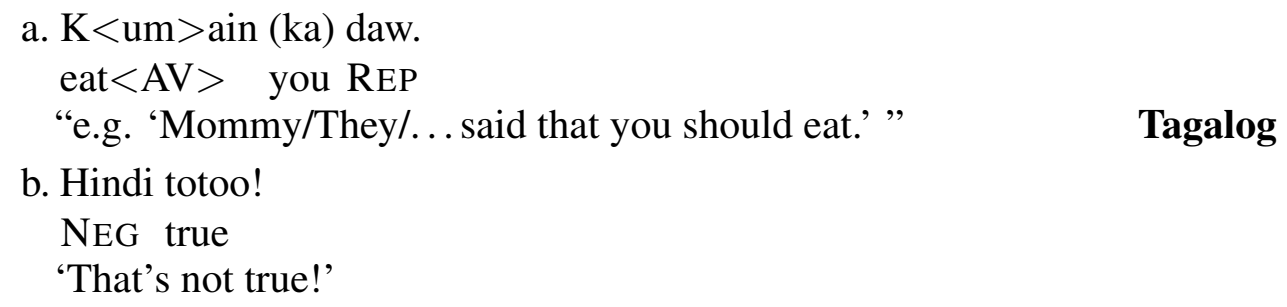

Attempting to replicate this judgment, however, is less than straightforward since no specific context is provided (as is also suggested by the somewhat schematic translation). However, I have attempted various concrete contexts which make salient different sorts of reporters and speakers consistently judge such dialogues marginal at best. Beyond this specific example, the overall pattern is very much the same as in YM, with declarative-like responses judged infelicitous: hindi 'no', oo 'yes', and other responses relating to truth. Responses typical for imperatives, however, are plainly acceptable such as sige 'ok' (borrowed from Spanish sigue 'go on') and negative desideratives with ayaw.

(13) Order Context: Our mother has told me to make sure that my younger sibling eats their bread. I tell my sibling:
a. Kainin mo daw ang tinapay mo eat.PT INDIR.2SG REP DIR bread your 'Eat you bread (she orders)!'
Tagalog
b. \#Hindi (totoo) // Ayaw ko // \#Oo // \#Totoo iyan // Sige (na) NEG true not.want INDIR.1SG yes true that okay now (nga) indeed \# 'It's not true.' // 'I don't want to.' // \#‘Yes' // \# 'That's true.' // Okay. Tagalog 
One nuance of the data worth commenting on is a slight asymmetry between the positive and negative declarative-like responses. While the positive declarative-like responses are judged completely out, one speaker for both languages indicated that the corresponding negative response was not quite as crashingly bad (though still dispreferred). One possible pragmatic explanation, then, is that the 'that's false' response implies that the speaker will not perform action since the reporter's supposed say-so had been taken to be the motivation behind the IMPReP. In contrast, the positive 'that's true' response does not make clear whether or not the responder will perform the action in question in this way. While we regard these declarative like responses on the whole as being infelicitous, we mention this detail here since it may help explain the judgment reported in (12) above.

\section{Two kinds of weakening with IMP $\mathrm{REP}$}

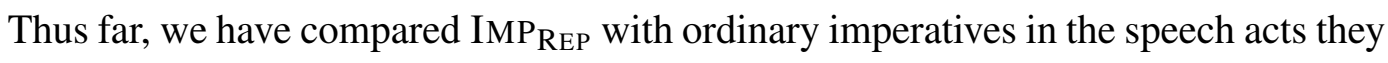
can be used to perform and the range of felicitous responses they permit. We turn now to address two kinds of 'weakening' effects in IMP REP that have been discussed informally in prior literature. Empirically, we show that both effects can be found in YM and Tagalog, but we argue that they are due to specific contextual factors, rather

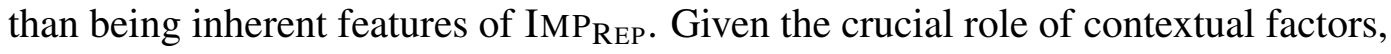
we argue in $\$ 5.3$ that both effects are best analyzed as consequences of more general pragmatic processes, rather than a direct result of the semantics of IMPREP.

\subsection{Weakening of directive force}

Aikhenvald (2010: p. 139) claims that reportatives in IMP $\mathrm{REP}_{\mathrm{P}}$ may 'attenuate' or 'soften' commands, and gives the examples in (14), implying that this possibility varies by language. While no precise model of imperative semantics is given, Aikhenvald states that "this is in line with content of a typical imperative-specific meaning known as 'degree' of command", thus diminishing "the requirement that the addressee should comply".

a. Marna-lu ma-nta nganta? spinifex-3pl get-IMPER REP

'Pick up the spinifex, won't you?' Warlpiri (Laughren 1982: p. 138)

b. Arrantherre kwele ntert-irr- $\emptyset$-aye!

2PLS REP quiet-INCH-IMPER-EMPH

'You mob are supposed to be quiet.' Mparntwe Arrernte, (Wilkins 1989: p. 393)

Taking at face value the claim that the examples in (14) exhibit 'softening' of 
An illocutionary account of reportative evidentials in imperatives

the obligation on the addressee, we might well ask whether this effect is a general feature of IMPREP or a feature of these specific examples. One reason for immediate skepticism is that these examples both are directive uses and examples of other sorts with or without 'softening' are not available in the sources cited. Although the notion of 'softening' may be intuitive in the case of commands, it is not clear from Aikhenvald's description what effect, if any, this 'softening' should have in other sorts of imperative speech acts. Should wishes, curses, warnings, and request uses similarly be 'softened'? What does 'softening' even mean for offers and disinterested advice cases, where there is arguably no requirement that the addressee comply to begin with?

Focusing even just on directive uses, however, we see for YM and Tagalog that there is no evidence for a specific propensity for 'softening' of the sort described. Rather, the intuitive 'degree of command' is impacted by the social and/or rational authority of the reporter along with that of the speaker (e.g. as discussed by Hamblin (1987), Kaufmann (2012) among others for ordinary imperatives). While a context which establishes a reporter with weak social authority intuitively softens the directive force as in (15a), just the opposite seems to be true in a context where the social authority of the speaker is strong, (15b). The child uttering (15b) intends to better ensure that the addressee will apply by appealing to an authority figure with more control over what the addressee should do. Indefinite or generic reporters as in (15c) may be likely to lead to 'weakening', but this is not a property of the reportative per se, merely the result of the indirect effect of different reporters' social/rational authority.

Uk' bin a wo'och k'eyem=o'

drink.IMPER REP your meal pozole-DISTAL

'Drink your pozole $\{$ she orders/he says/they say $\}$ !'

Yucatec Maya

a. Weak Social Authority Order Scenario: Our younger brother has told me to make sure my uncle eats his dinner. After talking to my brother, I turn to my uncle and say.

b. Strong Social Authority Order Scenario: Our mother has told me to make sure that my younger sibling eats their dinner. After talking to her, I tell my sibling.

c. Unspecified Reporter Order Scenario: We are sitting at the table and you aren't having your pozole. I say to you.

In sum, while individual utterances of IMP $\mathrm{REP}_{\mathrm{P}}$ may produce an intuitively softer directive force or 'degree of command', there is no evidence that this is a property of IMP $_{\text {REP }}$ per se. Instead, we have seen that to the extent that directive force differs in IMP $_{\text {REP }}$, it does not become consistently softer, but varies according to more general pragmatic reasoning about the speaker, addressee, and reporter. 


\subsection{Weakening of individual commitment}

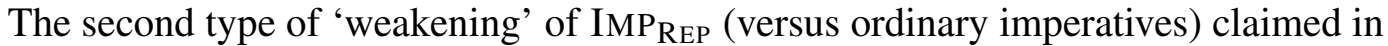
previous literature is the supposed lack of desire on the part of the speaker for the action in question to be performed (or perhaps lack of a commitment to having such a desire). This type of weakening is discussed by Thomas (2014), who argues for a NEUTRAL REPORT approach in part by citing the explicit denial in Mbyá in (16) in contrast to the ordinary imperative in (17).

(16) E-me'ẽ je chevy pe ka'ygua, va'eri nd-a-ipota-i.

2.IMPER-give REP me to mate, but NEG-A1-want-NEG

'Give me the mate, I heard, but I don't want it.'

Mbyá

E-me'ẽ ka'ygua Aureliano pe, va'eri nd-a-ipota-i re-me'̃̃

2.IMPER-give mate Aureliano to, but NEG-A1-want-NEG A2-give

ka'ygua ichu pe.

mate him to

'\#Give A the mate! But I don't want you to give him the mate.' Mbyá

For YM and Tagalog, analogous explicit denials with a negative desiderative following an IMPREP are also judged more or less felicitous:

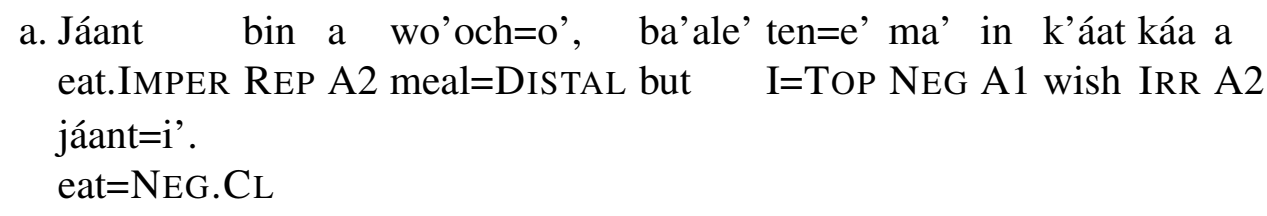

a. Jáant bin a wo'och=o', ba'ale' ten=e' ma' in k'áat káa a eat.IMPER REP A2 meal=DISTAL but I=TOP NEG A1 wish IRR A2 jáant $=\mathrm{i}$.

eat $=$ NEG.CL

'Eat your meal (he says), but me, I don't want you to eat it.' Yucatec Maya
b. ?Tumakbo ka daw araw-araw, pero ayaw kita-ng
run.IMPER DIR.2SG REP daily but not.want DIR2SG.INDIR1SG-LNK
tumakbo.
run
'Run daily (they say), but I don't want you to.'
Tagalog

Whether this observation leads us conclude that IMPREP differ in the updates they encode (i.e. in their meanings), however, depends on one's theory about what kind of updates imperatives encode in the first place. Thomas (2014)'s argument is based on the assumption that such sentences ought to be infelicitous due to their being logical contradictions. However, there are two potential counterarguments to this line of reasoning. First, as famously noted by Heim (1992) and illustrated in (19), the desires/preferences expressed by desiderative verbs like want need not be mutually consistent with one another. Imperatives, on the other hand, have been 
An illocutionary account of reportative evidentials in imperatives

argued to encode what Condoravdi \& Lauer (2012) call EFFECTIVE PREFERENCES, that is, preference structures where such inconsistencies have been resolved so as to guide action.

(19) Context: I don't want to teach at all next semester.

I want to teach Tuesdays and Thursdays next semester.

(Heim (1992))

Given this difference between preferences expressed by desideratives and those expressed by imperatives, we should not expect examples like (18) to be semantically ill-formed (see Condoravdi \& Lauer (2012) for further discussion). Rather, uttering an imperative typically gives rise to the inference that the speaker wants the addressee to perform the action described and it is this inference which gives rise to the contradictory feeling in (17) and its cross-linguistic counterparts. ${ }^{4}$ The obvious way to address this concern is to set aside conflicting desideratives and instead consider conflicting imperatives. For YM and Tagalog, conflicting IMPREP of this sort, as in (20), are somewhat less felicitous than (18), but not altogether infelicitous.
a. ?Jáant
bin verduras, ba'ale' (t-u
jaaj-il=e'
ma' a jantik. eat.IMPER REP vegetables but PREP-A3 true-REL=TOP NEG A2 eat 'They say to eat your vegetables, but (really) don't.'
Yucatec Maya
b. ?Tumakbo ka daw, pero (dapat)huwag ko-ng tumakbo! run.IMPER DIR.2SG REP but should NEG.IMP INDIR.2SG-LNK run 'They say to run, but don't run!'
Tagalog

While these data again confirm that particular utterances of IMP REP may exhibit 'weakening' of some sort, here too we argue in $\$ 5.3$ that this weakening is due to an independently observed pragmatic process. Specifically, we argue that such data are analogous to the pattern of denials in declaratives with reportatives that AnderBois (2014) has dubbed REPORTATIVE EXCEPTIONALITY and attributed to a more general phenomenon of pragmatic perspective shift.

In this section, we have seen two different kinds of 'weakening' found in IMP REP. While these have been taken as arguments that IMP $_{\text {REP }}$ contribute distinct meanings/updates, we have argued that the data are more complicated. Weakening of both sorts is due to particular aspects of the context and therefore warrants a pragmatic account instead. We sketch such accounts below in $§ 5.3$, but first turn to make a concrete proposal about the updates we take IMP $_{\text {REP }}$ to have in the first place.

4 The situation here is not unlike Moore's paradoxical sentences in which an inference triggered by the fact the act of assertion rather than its content produces a contradiction with a subsequent (see also Frank (1996: p. 84) on related cases with deontic modals). We set aside the question of whether the two inferences have precisely the same status as one another. 


\section{An illocutionary update semantics for IMP $\mathbf{I E P}_{\mathbf{R}}$}

Thus far, we have argued that $\mathrm{IMP}_{\mathrm{REP}}$, at least in YM and Tagalog, are fundamentally like other imperatives in terms of how they are used, i.e. constitute IMPERATIVES BY PROXY. In this section, we sketch an update semantics for IMPEP which fleshes out the sense in which they are semantically akin to other imperatives: $\$ 5$.1-5.2. Having done this, we return to the two types of weakening from $\S 4$, showing how they can be analyzed as pragmatic reasoning based upon this semantic proposal.

\subsection{Declaratives with reportatives in the discourse scoreboard}

In order to analyze the updates contributed by IMP $_{\mathrm{REP}}$, we of course need to have both an understanding of the updates contributed by imperatives as well as how reportatives modify updates in which they occur. To do this, we briefly review AnderBois (2014)'s 'scoreboard' semantics of reportative evidentials in declarative sentences in $\$ 5.1$ before turning to IMP REP themselves in $\$ 5.2$. We refer the reader to AnderBois (ms) for a detailed exposition and justification of the 'scoreboard' semantics for declaratives and imperative updates assumed here.

For declaratives in general, recent works have argued for one of two different updates for declarative sentences as in (21) (assuming for simplicity's sake a conversation with two participants, $a$ and $b$ ). First, it has been argued that declarative sentences conventionally encode an individual update that publicly commits $a$ to having adequate evidence supporting $p$ (Add $p$ to $\mathrm{DC}_{a}$ ). Second, declarative updates have been argued to contribute proposals to add $p$ to $a$ and $b$ 's Common Ground subject to $b$ 's approval (Add $p$ to Table $\left._{\{a, b\}}\right) .^{5}$

a. Input

\begin{tabular}{|l|l|l|}
\hline $\mathbf{a}$ & Shared $\{\mathbf{a}, \mathbf{b}\}$ & $\mathbf{b}$ \\
\hline \hline $\mathbf{D C}_{a}$ & Table $_{\{a, b\}}$ & \\
\hline
\end{tabular}

b. Declarative update (Proposal and Commitment by $a$ )

\begin{tabular}{|c|c|c|c|}
\hline $\mathbf{a}$ & & Shared $\{\mathbf{a}, \mathbf{b}\}$ & b \\
\hline & & $p$ & \\
\hline $\mathbf{D C}_{a}$ & $p$ & $\mathbf{C G}_{\{a, b\}}$ & $\mathbf{D C}_{b}$ \\
\hline
\end{tabular}

c. Acceptance (by $b$ )

5 Depending on the linguistic means of acceptance by $b, p$ may also be added to $\mathrm{DC}_{b}$. For example, Gunlogson (2001) argues that an acceptance using English yes achieves this effect, whereas implicit acceptance moves and some other explicit moves such as $o k$ do not produce this effect. 
An illocutionary account of reportative evidentials in imperatives

\begin{tabular}{|l|lr|l|}
\hline $\mathbf{a}$ & Shared \{a,b\} & $\mathbf{b}$ \\
\hline \hline & Table $_{\{a, b\}}$ & \\
\hline $\mathbf{D C}_{a}$ & $\mathbf{C G}_{\{a, b\}}$ & $p$ & $\mathbf{D C}_{b}$ \\
\hline
\end{tabular}

These two updates have not only different conceptual underpinnings, but different empirical arguments supporting them as well. For example, Gunlogson (2001) argues for the public commitment update based on the ways in which rising intonation modifies the speaker's commitment (while equally putting the issue of whether $p$ on the Table for discussion). Conversely, Farkas \& Bruce (2010) argue for the CG proposal update based upon the uniform effect that response particles like yes and no have across sentence types which differ in their speaker commitments (i.e. declaratives and interrogatives). We refer the reader to AnderBois (ms) for a more detailed discussion of empirical and conceptual bases for these two updates.

While often discussed as competing hypotheses about declarative updates, AnderBois (2014) argues that reportative evidentials show that both updates are needed and in particular claims that illocutionary reportatives in declaratives like (5) leave the proposal intact, but alter the public commitment (see also AnderBois (2016)). This theory, of course, shares much in common with previous illocutionary accounts, differing principally in that it is specifically $\mathrm{DC}_{x}$ which is modified by reportatives rather than the sincerity conditions of an actual speech act (Faller (2002)) or the CG itself (Murray (2014)). A declarative with a reportative such as (22) is claimed to contribute the 'asymmetric' update in (23).

(22) Scenario: I am talking on the phone with a friend to ask about the weather in our town so we can decide whether to bring umbrellas and I tell you:

Táantik bin u chuunul u toosol ja'=e'

IMM.PAST REP A3 start A3 sprinkle water=TOP

'It just started to sprinkle (he says).'

(23) Declarative update w/ Reportative bin:

\begin{tabular}{|ll|l|l|}
\hline $\mathbf{a}$ & Shared $\{\mathbf{a , b}\}$ & $\mathbf{b}$ \\
\hline \hline & Table $_{\{a, b\}}$ & $p$ & \\
\hline $\mathbf{D C}_{a}$ & $\operatorname{REP}(p)$ & $\mathbf{C G}_{\{a, b\}}$ & $\mathbf{D C}_{b}$ \\
\hline
\end{tabular}

\subsection{IMP IMP $_{\text {in the discourse scoreboard }}$}

While there has often been an impulse to tie imperatives to actions or commands more directly, as discussed in $\$ 4.2$ above, many recent works have proposed that imperatives instead encode preferences of particular kinds. Specifically, we follow Condoravdi \& Lauer (2012) in taking imperatives to express what they call EFFECTIVE PREFERENCES, i.e. preferences where inconsistencies have been resolved so as 
to guide joint action. Given the conceptual similarity with the COMMON GROUND as well as empirical arguments discussed by AnderBois (ms), we take imperatives to contribute proposals to update the COMMON PREFERENCES of the conversational participants: $\operatorname{CPref}_{\{a, b\}}$ (see also Starr (2013), von Fintel \& Iatridou (t.a.) for similar ideas about imperative updates). Specifically, we assume ordinary imperatives encode proposals to update $\operatorname{CPref}_{\{a, b\}}$ with a preference for the proposition denoted by the rest of the sentence (typically including a null second-person subject) over its negation. ${ }^{6}$

Imperative update (proposal by $a$ ):

\begin{tabular}{|l|ll|l|}
\hline $\mathbf{a}$ & Shared $\{\mathbf{a}, \mathbf{b}\}$ & $\mathbf{b}$ \\
\hline \hline & Table $_{\{a, b\}}$ & $p>\neg p$ & \\
\hline $\mathbf{D C}_{a}$ & $\mathbf{C G}_{\{a, b\}}$ & & $\mathbf{D C}_{b}$ \\
\hline & $\mathbf{C P r e f}_{\{a, b\}}$ & & \\
\hline
\end{tabular}

Above, we followed AnderBois (2014) in taking reportatives in declaratives to leave the proposal to update the CG unaltered, while committing the speaker only to $\operatorname{REP}(p)$, rather than $p$ itself. Extending this to imperatives, we claim that IMPREP leave the proposal to update $\operatorname{CPref}_{\{a, b\}}$ unaltered while again adding the information that a second or third-hand reporter (i.e. someone other than $a$ and $b$ ) holds this preference). We see this semantics illustrated for the IMPREP in (25) in (26).

(25) Order Scenario: Our mother has told me to make sure that my younger sibling eats their dinner. After talking to her, I tell my sibling:

Uk' bin a wo'och k' eyem=o'

drink.IMPER REP your meal pozole-DISTAL

'Drink your pozole (she orders)!'

(26) Imperative update w/ Reportative bin:

\begin{tabular}{|c|c|c|}
\hline $\mathbf{a}$ & Shared $\{\mathbf{a}, \mathbf{b}\}$ & b \\
\hline & Table $_{\{a, b\}}$ & \\
\hline $\mathbf{D C}_{a} \quad \operatorname{REP}(p>\neg p)$ & $\mathbf{C G}_{\{a, b\}}$ & $\mathbf{D C}_{b}$ \\
\hline & $\operatorname{CPref}_{\{a, b\}}$ & \\
\hline
\end{tabular}

Returning to the data in $\S 3$, the account captures the fact that IMPREP can be used in the same range of potential speech acts as other imperatives since the same proposal is made. While we do not provide a concrete analysis of various responses in $\mathrm{YM}$ and Tagalog here, response particles in other languages have been claimed to make reference to the Table and therefore ought to be uniform between IMPREP

6 Following Villalta (2008)'s work on desideratives, we may well want to take $\neg p$ as a special case of a more general preference for $p$ over contextually relevant alternatives. We leave it to future work to determine which view is superior for imperatives. 
An illocutionary account of reportative evidentials in imperatives

and other imperatives. The reportative in this account has no direct effect on the illocutionary update the IMP $\mathrm{REP}_{\text {C }}$ contributes. As we will see in a moment, however, the reportative has indirect effects on inferences drawn by the addressee, including especially the speaker's personal preference in the matter at hand.

\subsection{Two kinds of softening revisited}

In $\S 4$, we examined two types of weakening found with IMP $_{\text {ReP }}$, arguing that both are due to pragmatic properties of imperatives and reportatives more generally. The first type of weakening we discussed was the apparent 'softening' of directive force in certain command-like uses. Under the account here, such variability is expected since the semantics for imperatives already presumes various sorts of pragmatic reasoning to account for polyfunctionality in the first place (see, e.g. Condoravdi \& Lauer (2012) and Kaufmann (2012)). For the addressee to conclude that the speaker intends a command, request or other directive use, they will reason about the goals and the social and/or rational authority of the conversational participants. The same sort of reasoning applies to IMP $_{\mathrm{REP}}$, merely differing in that the these same features of the reporter will also enter into the equation. The role of the speaker is not entirely obviated, however, since a rational speaker will typically not make a proposal that conflicts with their effective preferences (see AnderBois (2016) for discussion about the analogous effect in declaratives). While there are many details to be elaborated upon here, the basic point is that variability in directive force is a feature of ordinary imperatives and the pragmatic reasoning underlying it plausibly explains similar variation in IMP $\mathrm{REP}_{\text {. }}$

The second type of weakening we found was the ability of the speaker to explicitly deny their preference for the imperative proposition, either using a desiderative or, more marginally, a conflicting imperative. The at least marginal felicity of such sentences is, on the face of it, unexpected with the semantics proposed above. However, as illustrated above in (6), this sort of denial has an analogue in declarative sentences like (27), where the speaker explicitly denies the scope of the reportative.

a. Ma' bin t-in máans-(aj)-e eeksaamen=o'

Neg ReP PFV-A1 pass-StATUs-Def exam=DistAL 'I didn't pass the exam reportedly, ...'

b. ba'ale' t-u jaaj-il=e' t-in máans-aj.

but PREP-A3 true-REL=TOP PFV-A1 pass-STATUS

'... but actually I passed.'

Yucatec Maya

For declarative cases like (27) and their cross-linguistic counterparts, AnderBois (2014) argues that the felicity of such denials is due to pragmatic perspective shift, which reportatives facilitate indirectly by making salient an alternative perspective: 
that of the reporter. Beyond the superficial similarity between the two cases of denials, two more detailed aspects of the data suggest the same dynamic is at play. First, outside of cases with such explicit denials, we have argued that the same update to the Table is made (e.g. based on the range of felicitous responses, resultant speech acts). Second, in both cases, such denials are only felicitous in cases where other perspectival language highlights the shift in perspective. In IMP REP $_{\text {denials, }}$ these include the use of first person attitude verbs in (18), contrastive elements like Tagalog pero and YM ba'ale' in (18-20), and the contrastive use of clausal topics tene' 'as for me' and tu jaajile' 'really' in (18a) and (18b). Versions of these denials without such elements (or other similar elements such as special intonation) are judged infelicitous in comparison to the at least marginally accepted forms. In short, while researchers may commonly choose to elicit explicit denials, this is not the typical use of IMPREP (nor of reportatives in declaratives) and their felicity requires additional contextual, and typically linguistic, support.

\section{Conclusions}

Recent decades have seen the growth of a vibrant body of research which rigorously examines the contributions of evidentials and their interactions with sentence type/illocutionary mood. One key source of evidence in investigating this area - and in particular in the debate between so-called modal versus illocutionary analyses has been data regarding evidentials in interrogative sentences. While evidentials in imperatives are less pervasive across languages and are only attested for reportatives, we hope to have shown that data from imperatives with reportative evidentials can similarly inform not only the study of evidentials, but also the meanings of imperatives themselves.

However, while we have argued that reportatives in IMP $_{\text {REP }}$ warrant an illocutionary account, we cannot simply conclude that Tagalog daw and YM bin are illocutionary evidentials. This is because looking beyond IMPREP, we find quite different properties of the two evidentials in other sentence types. For example, while Tagalog daw is felicitous in 'interrogative flip' scenarios, YM bin is robustly infelicitous in such uses. Within declaratives, Tagalog daw is embeddable in a wide range of environments (e.g. as argued by Schwager (2010) and Kierstead (2015)), while YM bin does not appear to ever be embeddable. Such data, therefore, call into question the viability of the modal-illocutionary dichotomy (see Korotkova (2016) for a similar conclusion) or at the very least, suggests that individual evidentials may have both types of uses. 
An illocutionary account of reportative evidentials in imperatives

\section{References}

Aikhenvald, Alexandra. 2004. Evidentiality. Oxford University Press.

Aikhenvald, Alexandra. 2010. Imperatives and commands. Oxford University Press.

AnderBois, Scott. 2012. Indefiniteness and the typology of implicit arguments. In Nathan Arnett \& Ryan Bennett (eds.), West Coast Conference on Formal Linguistics (WCCFL) 30, 43-53.

AnderBois, Scott. 2014. On the exceptional status of reportative evidentials. In Semantics and Linguistic Theory (SALT) 24, 234-254.

AnderBois, Scott. 2016. Semantics and pragmatics of (not-)at -issueness in Yucatec Maya attitude reports. Semantics \& Pragmatics 9(19).

AnderBois, Scott. ms. Illocutionary revelations: Yucatec maya bakáan and the typology of miratives.

Bittner, Maria. 2014. Temporality. John Wiley and Sons.

Ceong, Hailey Hyekyeong. 2016. Korean hearsay constructions and speech act phrases. In Annual Conference of the Canadian Linguistic Association, .

Condoravdi, Cleo \& Sven Lauer. 2012. Imperatives: meaning and illocutionary force. In Empirical Issues in Syntax and Semantics 9, .

Faller, Martina. 2002. Semantics and pragmatics of evidentials in Cuzco Quechua: Stanford PhD dissertation.

Faller, Martina. 2007. The Cusco Quechua reportative evidential and rhetorical relations. Linguistiche Berichte 14. 223-252.

Farkas, Donka \& Kim Bruce. 2010. On reacting to assertions and polar questions. Journal of Semantics 27(1). 81-118.

Farkas, Donka \& Floris Roelofsen. 2015. Polarity particle responses as a window onto the interpretation of questions and assertions. Language 91(2). 359-414.

Fillmore, Charles. 1969. Types of lexical information. In Studies in syntax and semantics, 109-137. Reidel.

von Fintel, Kai \& Sabine Iatridou. t.a. A modest proposal for the meaning of imperatives. Ms, submitted to a volume on Modality across syntactic categories (Oxford University Press), ed. by Ana Arregui, Marisa Rivero, and Andrés Pablo Salanova.

Frank, Anette. 1996. Context dependence in modal constructions: University of Stuttgart $\mathrm{PhD}$ dissertation.

Gunlogson, Christine. 2001. True to form: Rising and falling declaratives as questions in English: UCSC PhD dissertation.

Hamblin, C.L. 1987. Imperatives. Basil Blackwell.

Heim, Irene. 1992. Presupposition projection and the semantics of attitude verbs. Journal of Semantics 9. 183-221.

INEGI, Instituto Nacional de Estadística y Geografía. 2009. Perfil sociodemográfico 
de la población que habla lengua indígena. Online at: http://www.inegi.org.mx. Kaufmann, Magdalena. 2012. Interpreting imperatives. Springer.

Kierstead, Gregory. 2015. Projectivity and the Tagalog reportative evidential. The Ohio State University MA thesis.

Korotkova, Natalia. 2016. Heterogeneity and uniformity in the evidential domain: UCLA PhD dissertation.

Korotkova, Natasha. 2015. Evidentials and (relayed) speech acts: Hearsay as quotation. In Semantics and Linguistic Theory (SALT) 25, 676-694.

Laughren, Mary. 1982. A preliminary description of propositional particles in Warlpiri. In Work Papers of the Summer Institute of Linguistics, Australian Aborigines Branch A 6, 129-163. SIL.

Lim, Dong Sik. 2010. Evidentials and interrogatives: a case study from Korean: USC PhD dissertation.

Lucy, John. 1993. Metapragmatic presentationals: Reporting speech with quotatives in Yucatec Maya. In John Lucy (ed.), Reflexive Language: reported speech and metapragmatics, 91-125. Cambridge University Press.

Murray, Sarah. 2010. Evidentiality and the structure of speech acts: Rutgers $\mathrm{PhD}$ dissertation.

Murray, Sarah. 2011. A Hamblin semantics for evidentials. In Semantics and Linguistic Theory (SALT) 19 (2009), 324-341. CLC Publications.

Murray, Sarah. 2014. Varieties of update. Semantics \& Pragmatics 7(2). 1-53.

Schachter, Paul \& Fe T. Otanes. 1972. Tagalog Reference Grammar. University of California Press.

Schwager, Magdalena. 2010. On what has been said in Tagalog. In Evidence from evidentials, 221-246. University of British Columbia Working Papers in Linguistics.

Starr, William. 2013. A preference semantics for imperatives. Ms. Cornell.

Thomas, Guillaume. 2014. Embedded imperatives in Mbyá. In North East Linguistic Society (NELS) 43, 181-194. Graduate Linguistic Student Association of the University of Massachusetts, Amherst.

Villalta, Elisabeth. 2008. Mood and gradability: an investigation of the subjunctive mood in spanish. Linguistics and Philosophy 31. 467-522.

Wilkins, David P. 1989. A grammar of Mparntwe Arrernte: Australian National University $\mathrm{PhD}$ dissertation. 
An illocutionary account of reportative evidentials in imperatives

Scott AnderBois

Brown University

Box 1821

190 Thayer St.

Providence, RI 02912

scott_anderbois@brown.edu 